\title{
Ethnomathematics: past and future
}

\author{
Ubiratan D'Ambrosio
}

\begin{abstract}
Each culture develops ways, since the Paleolithic era, styles and techniques of doing, and responses to the search of explanations, of understanding and of learning. They basically respond to "how" and "why". In the human species, early attempts to explain and to understand lead to the search for origins, which leads to myths. All these are organized as systems of knowledge and religions. These systems of knowledge lead to the concept of Ethnomathematics. After a report on the practice of Ethnomathematics and the evolution of theoretical reflections since pre-historic times to the present, I will discuss some new trends I recognize in the theory and practice of Ethnomathematics. I will refer to different cultural environments and the consequents of the growing migratory dynamics in the entire world. The move towards globalization and internationalization of education favors the reinforcement of local considerations. Glocalization has consequences for the future of Ethnomathematics as research program with pedagogical implications.
\end{abstract}

Keywords: Encounters. Ethnomathematics. Glocalization.

\section{Etnomatemáticas: pasado y futuro}

Resumen: Cada cultura, desde la era paleolítica, desarrolla formas, estilos y técnicas de hacer y de buscar respuestas para explicaciones, de comprensión y de aprendizaje. Buscam responder, basicamente, al "cómo" y al "por qué". En la especie humana, los primeros intentos de explicar y comprender conducen a la búsqueda de los orígenes, lo que conduce a los mitos. Todos ellos están organizados como sistemas de conocimiento y religiones. Estos sistemas de conocimiento conducen al concepto de Etnomatemática. Después de una revisión sobre la práctica de la etnomatemática y la evolución de las reflexiones teóricas, desde los tiempos prehistóricos hasta el presente, analizaré algunas nuevas tendencias que reconozco en la teoría y la práctica de la etnomatemática. El el presente artículo, me referiré a diferentes entornos culturales y las consecuencias de la creciente dinámica migratoria en todo el mundo. El movimiento hacia la globalización y la internacionalización de la educación favorece el refuerzo de las consideraciones locales. La glocalización tiene consecuencias para el futuro de la etnomatemática como un programa de investigación con implicaciones pedagógicas.

Palabras clave: Encuentros. Etnomatemáticas. Gocalización.

Ubiratan D'Ambrosio Doctor in Mathematics by Universidade de São Paulo (USP). Orofessor of the Postgraduate Program in Mathematics Education by the Universidade Anhanguera de São Paulo (UNIAN). São Paulo, Brasil.

(iD https://orcid.org/0000-0003-0564-158X

$₫ \underline{\text { ubi@usp.br }}$

Received in 23/10/2019

Accepted in 02/12/2019

Published in 04/03/2020

\section{Etnomatemática: passado e futuro}

Resumo: Cada cultura, desde a era paleolítica, desenvolve formas estilos e técnicas de fazer, e responder à busca de explicações, de compreensão e de aprendizagem. Buscam responder, basicamente, o "como" e o "por que". Na espécie humana, as primeiras tentativas de explicar e compreender conduziram à busca das origens, o que leva aos mitos. Tudo isso é organizado como sistemas de conhecimento e religiões. Esses sistemas de conhecimento levam ao conceito de Etnomatemática. Após um relato sobre a prática da Etnomatemática e a evolução das reflexões teóricas desde os tempos préhistóricos até o presente, discutirei algumas novas tendências que reconheço na teoria e na prática da Etnomatemática. No presente artigo, vou me referir aos diferentes ambientes culturais e às consequências da crescente dinâmica migratória em todo o mundo. $O$ movimento em direção à globalização e à internacionalização da educação favorece o reforço de considerações locais. A glocalização tem consequências para o futuro da Etnomatemática como um programa de pesquisa com implicações pedagógicas.

Palavras-chave: Encontros. Etnomatemática. Glocalização. 


\section{The scenario: from local to global and to glocal}

Since early times, the human species struggle, like every living being, to survive in their natural environment. But uniquely among all other species, humans go beyond survival and transcend immediate physiological needs and start questioning: How and why? Who am I? Who are the others? The human species go even beyond these immediate questions and their natural environment. Humans try to understand, to explain and to cope with natural facts and phenomena beyond the local environment, observe skies and the cosmos and move. It arises a sense of belonging to a global universe, recognizing different peoples and environments.

Addressing archetypal and cosmogonic issues leads to a degree of supremacy of man over the other components of the animal kingdom and indeed over all the creation. The human species develop an anthropocentric perspective. These are the first steps for creating myths which are the foundations of the social practice of religions. Mythological deities created man in the condition of servitude. Deities might be incarnated as privileged humans and this leads to the emergence of powerful humans, with are considered agents and even incarnation of deities. In many cases, affirming their submission by sacrificing animals and even fellow human beings, erecting monuments and temples and creating images honoring the deities. Humans soon recognized their power of life and death, of mutilating and subduing all other beings, including humans, and power over all natural resources and the geographical space, venturing to extend this power to the cosmos.

The exercise of this power was legitimized to please deities or their agents. Social groups became subordinated to a hierarchy of power. The results increase in human population, causing unsustainable consumption of food, water, energy, and materials, and irreparably damaging the natural world. The broad belief on the rightness of the supremacy of humans over the entire creation constitutes the prevalent human worldview. This belief manifest blinds the human collective to the wisdom of limitations in several ways. An insatiable more characterizes progress and human expansionism, and threatening ecological and societal stability.

Each culture developed, since the Paleolithic era, ways, styles and techniques of doing and responses to the search of explanations, of understanding and of learning. Early attempts to explain and to understand lead to the search for origins, which leads to myths which are the roots of traditions. All these are organized as systems of knowledge and religions. Basically, they respond to "how" and "why" and are organized as practices and theories, which are not in dichotomy. Practices and theories are part of the same quest: who I am and why I am. 
Having access to different cultural environments, which is a trend as a consequence of migratory dynamics, we recognize specificities of the roots but also universal similarities. Some scholars use the neologism glocal, which means reflecting about the global context without losing perception of the local context. This includes myths and traditions, practices and theories. The practices and theories are organized as systems of knowledge, among them those of a mathematical nature, dealing with numbers, forms and inference.

As we will see later, these are the Ethnomathematics of each natural and sociocultural environment, a local concept. The growing mood of globalization and internationalization of every human activity, particularly religion, commerce and economy, science and education, frames global behavior with special attention to local considerations, which is glocalization. Trivial examples of glocalization are fast-food (a McDonald hamburger in Tokyo is different from McDonald hamburgers - the same Corporation — in New York, Dubai, Moscow), rap and haircuts suit local conditions, religious cults and rituals are adapted to local communities. The same should occur with Science and Education.

Glocalization is a facet of the dynamics of cultural encounters, which expose how different cultures deal with various areas of human experiences and how they organize them. In 1960, the eminent algebraist Yasuo Akizuki proposed an emphasis on the reflective side of mathematics, looking into the world as a whole. He makes a strong point for the introduction of the History of Science and Mathematics in all levels of teaching. The most interesting point in his argument is the recognition that mathematics is a cultural product, present in Asia. He says that:

Oriental philosophies and religions are of a very different kind from those of the West. I can therefore imagine that there might also exist different modes of thinking even in mathematics. Thus I think we should not limit ourselves to applying directly the methods which are currently considered in Europe and America to be the best, but should study mathematical instruction in Asia properly. Such a study might prove to be of interest and value for the West as well as for the East (AKIZUKI, 1959, p. 288-289).

It is also very relevant the study of the distinguished historian Lloyd (2009) on the organization of areas of knowledge as disciplines in various cultural environments and about the elite of practitioners. Specifically, he calls Biomedicine the academic practices and theories developed mainly in Modern Europe. At a point he claims that:

Biomedical practitioners, with a battery of tests to call on, may pronounce a patient all clear: alternative practitioners, on the basis of their different criteria, may do the same. But the patients themselves have their opinion and feelings, which medical experts may label ignorant, misguided, deluded, even neurotic, but which from the patients' consumers' - perspective are what counts. Biomedicine is no doubt set to make even greater advances in the techniques at its command. But the possibilities of mismatch 
between what biomedicine pronounces to be the case and what individual patients feel, are unlikely ever to be completely removed. If so, alternative styles of medicine, with their more or less articulate elites to promote them, are likely to continue to bear witness to the complexities of our understanding of what it is to be truly well, and would surely be foolhardy to suppose that biomedicine has nothing to learn from the rivals (LLOYD, 2009, 91-92).

In this paper I will discuss how glocalization has positive consequences for the future of Ethnomathematics as a research program with pedagogical implications.

\section{Observation, Comparison, Evaluation, Organization, Inference}

Knowledge is the result of action generated by an individual, who processes information received from reality. Innumerable attempts to define reality, which has taken the intellectual energy of philosophers of all times. I simply consider reality to be everything, that is, natural and supernatural (cosmic and spiritual) phenomena and facts, physiological and sensorial, emotional and psychic reactions, social interaction, indeed everything, which are permanently changing.

There are animal behaviors, relating body and mind, which generate actions of an individual to process information received from reality. How are these actions characterized and how did they evolve is one of the enticing areas of scientific research? The first action of an individual when facing a situation or problem, is observation and activation of memory to recognize previous experiences. They acquired special characteristics in the evolution of human species. We recognize (as yet) five basic actions: observation, comparison, evaluation, organization, inference. Observation is possible by activating the available senses, as it is fictionally shown in the marvelous novel The Country of the Blind, written by Herbert George Wells in 1904.

If one sense lacks, for example, vision, others senses, as well intuition and other possible extra-sensorial perceptions, are activated. This is a very touchy theme in the area of mind and consciousness. These steps may be materialized in doing, which deals with or explains the ad hoc situation or problem faced. This is the typical behavior of all animal species, usually called instinct, resorting to the capacities of communicating, learning and remembering. Humans bring another dimension to communication, which seemingly are not present in other animal species, such as languages, long-term memory, historical record-keeping and planning for the future.

More than any other difference, while animals act as a response to present perceptions, beliefs and motives, humans go beyond the present and judge, resorting to the five basic behaviors, which are redefined and expanded, the outcome, the effects, of the actions. If our action provides 
adequate response to the situation or problem, it is accepted and registered. This gives rise to knowledge, particularly science, and morality.

After observation, the next step is comparison, probably the first opportunity to exert an evaluation, such as bigger or smaller $\rightarrow$ dimension $\rightarrow$ measurement; more or less $\rightarrow$ quantification ; like or dislike $\rightarrow$ preferences ; right or wrong $\rightarrow$ values, which are intrinsic to human behavior. Next step is the organization of what was observed and evaluated, followed by a classification. The sets of observed, evaluated, organized, classified facts and phenomena allow for inference, drawing conclusions and generating methods.

\section{From ad hoc solutions and explanations to methods and theories}

Let us figure out how, in the evolution of human species, these steps proceed building up knowledge. We notice that in dealing with an ad hoc situation or problem, we do something and it works, then we do it again and again and repeatedly it works, and we do it in similar situations or problems and it works. This means that we have a method.

Synthesizing, an ad hoc dealing with a situation or problem requires observing, then comparing, classifying, measuring, quantifying and organizing. After evaluating the result, we infer and draw conclusions which lead to a method. I use inferring in the sense of a mental experiment that goes from premises (which are agreed or believed to be true or already known) to conclusions, thus to new knowledge. Once we have a method, it is natural for the human species questioning "why does this method work? This leads to coherent sets of justifications, which are called theories. A theory is based on principles about generic, not specific, methods, facts and phenomena. It can thus lead to organize such principles into new methods, facts and phenomena. These organizations, which may be unrelated to the original facts and phenomena, are called inventions, both intellectual and material.

How did this happened throughout history? There are evidences that life in the planet Earth dates back to about $4 \times 10^{9}$ years. Life is characterized by the capability of continuity through selfreproduction. About $10^{9}$ years ago occurred sexual differentiation of more complex forms of life and are evidence of early forms of animal life about half a billion years ago. The early bipeds sahelanthropus tchadensis appeared in the Sahara, today Republic of Chad, about 7 million years ago and about 6 million years ago there are fossils of the Orrorin tugenensis in Kenya's Tugen Hills. These are considered, by inconclusive evidence, to probably be the first bipedal hominin species. 
Every once-a-while fossils are un-earthened and provide new elements for controversial theories of human evolution. The Australopithecus, which existed from 4 to 2 million years ago, evolved as homo erectus, migrated out of Africa about 2 million years ago, and spread throughout Eurasia and to other regions of the planet. In these regions they evolved, leading to, among others, the species homo neanderthalensis and homo denisova, which lived in Europe and Asia approximately from 400,000 to 40,000 years ago. These species adapted to colder environments living in shelters, mainly caves, made and wore clothing and controlled fire. They hunted large animals and developed tools and instruments. They buried the dead and made ornamental and symbolic objects. It is even possible that they practiced cults and developed myths. This is the emergence of symbolic thinking.

The species homo sapiens evolved in Africa about 200,000. They gathered and hunted food and moved extensively to look for more favorable environments. Eventually they reached Europe and Asia and coexisted with homo neanderthalensis and homo denisova until approximately 40,000 BP 1 . and could have shared habitats in what must have been a complex relationship, involving competition and possibly interbreeding. There is growing interest in learning more about Neanderthals. Particularly interesting are recent results about symbolic and ritualistic behavior of Neanderthals, which places the origins of Art and the emergence of myths at about the same time as the origins of early tools. The Howiesons Poort culture, that flourished about 60,000 $\mathrm{BC}$ in the Eastern Cape province in South Africa, is an example of lithic technology ${ }^{2}$ and the emergence of decorative arts, characteristic of early symbolic culture. Survival and transcendence have been together since earliest signs of intelligent behavior of our species, particularly through art.

There is the emergence of a protomarket in communities and also in the encounter of different societies. Archeologists found evidence of exchange of gifts with symbolic meaning. This may be a kind of dowry in the process of acquiring mate partners. There are also indications of acquiring raw material for lithic technology.

\section{Past, present and future and the pulsions of survival and transcendence}

The species homo seems to be the only that developed a sense of past and of future,

\footnotetext{
1 The initials BP stand for years before present, which is used by archaeologists, geologists, and other scientists. It refer to radiocarbon ages and results from other radiometric dating techniques.

2 In archeology, lithic technology includes a broad array of techniques and styles that are used to produce usable tools from various types of stone.
} 
transcending the present. The human species are characterized by the association of the pulsion of survival, common to all living beings, and of the pulsion of transcendence, unique to the human species. In the human species, action manifests, basically, in two ways:

- actions which lead to survival of the individual and of the species, and the satisfaction of needs, common to all living beings, which are performed in the present, in the instant; this I call the pulsion of survival;

- actions which satisfy man's needs for explanations, for understanding, for prediction, for creating, in response to will, which lead to transcend the instant and to search the past, sometimes asking for reasons and intentions of the divine for what happened; and probing into the future, wishing, willing, hoping and warning and "asking" the divine for what will be; this complex questioning I call the pulsion of transcendence.

With the emergence of the species homo, tools, instruments, equipment, techniques came into playing a role in the relations between individual, other/society, and nature.

Knowledge in the human species is recognized in the acquisition of abilities, capabilities, ways of doing, of explaining, of understanding, of coping with everyday needs for surviving, which leads to invention of different instruments transcendence, and takes the form of distinct ways of transcending, which leads to representing and communicating natural facts and phenomena. Representations, which are the quintessence of communication, are primitive forms of commerce and social stratification related to agriculture. Agrarian societies developed socially complex systems, which gave origins for social inequality that may be the roots of capitalism, as proposed by Anthropologist Thomas P. Leppard (2019).

Humans are new in the timeline of the evolutionary history of life $\left(7 \times 10^{6}\right.$ against $\left.10^{9}\right)$. Human behavior is the response to pulsions of survival and of transcendence. In the course of its evolution, the species developed systems of knowledge, in the broad sense of responses to needs and will, taking into account practical and mythical motivations. In response to different natural environments, different systems of knowledge were developed, with the same aims. These systems include, invariantly, in all the times and everywhere in the World, strategies of observing, of comparing, of classifying, of evaluating, of quantifying and measuring, of representing and inferring and of communicating.

These strategies are the support of what I call Ethnomathematics, which deals with the generation, the intellectual and social organization and the transmission and diffusion of different ways, styles, modes (tics) of explanation, understanding, learning, coping with and probing beyond 
(mathema) the immediate natural and socio-cultural environment (ethno). The tics of mathema in different ethnos give rise to the concept of Ethnomathematics. What we call Academic or School Mathematics is the Ethnomathematics originated in the ethno of the Mediterranean Basin, which expanded to the entire Europe and after the great navigations of since the 15th century to the entire world. I will not elaborate further on this, since it is amply presented in several of my writings.

It is impossible to deny the mutual influence of the exposition of different cultures in the generation, the intellectual and social organization and the transmission and diffusion of tics of mathema in different ethnos. Although Ethnomathematics, hence Academic and School Mathematics, as any form of knowledge, have local roots, it is undeniable its global reach. This is a major issue in the history of ideas.

Ways, styles, modes (tics) of explanation, understanding, learning, coping with and probing beyond (mathema) the immediate natural and socio-cultural environment (ethno) also give origin to different forms of knowledge, such as languages, myths, religions, arts and to sets of values which regulate behavior. The complex of the strategies for the generation, the intellectual and social organization and the transmission and diffusion of different forms of knowledge and their consequences characterizes a culture. This is one of countless concepts of culture, which works for this narrative.

As we can easily infer from the elaboration of my concept of culture, the strategies are contextualized in the natural, social, and mythological environment. It is undeniable the contextual essence of a culture, although there may occur similar strategies in different environments. There are cultural manifestations encountered in different cultures.

My main interest is to understand the origins and the evolution of the strategies leading to a culture. A method to do this is to look for the evolution of the full cycle of generation, of intellectual and social organization, and of transmission and diffusion of knowledge in that context. Of course, this cycle changes, as a result of its internal evolution of the practices and theories grouped as languages, myths, religions and the set of values. They are not static. But there is, clearly, an encounter of different cultures, motivated by several factors, such as territorial disputes and acquisition of natural resources, search of mating partners, mythical motivation, commercial exchanges, wars of conquest and other reasons. There is in the mutual exposition of the encounter of cultures, a dynamic process of change. One culture influences and is influenced by the other. I call this process the dynamics of cultural encounters. 
The dynamics of the encounter of cultures may result in various degrees of assimilation, of subordination and even of suppression of one of them. What occurs, in most cases, is a syncretism, giving origin to new systems of knowledge. Every encounter reveals ideological problems and conflicts and it is impossible to remove completely the traces of the assimilated or the suppressed system. Extant traces of the original cultures in the encounters are always present. Ways of doing and of knowing always reveal subtle peculiarities and to identify them is a great challenge to researchers. Culture is a complex of many factors, with an intrinsic fuzziness.

\section{The future}

In the current globalized world scenario, Science and Mathematics are essential for daily life. Technology is present in every moment of our life, in the production and utilization of equipments, in the economic needs, in moving around in urban centers and in getting information and communicating. But there is a hypertrophy of scientific and mathematical knowledge between countries. Although this may be traced back to Antiquity, it intensified in the colonial empires during the colonization and decolonization period.

Nowadays some countries have more intense investment and production, both of academic and school science and mathematics, but when compared with central nations, the gap of achievements is increasing. The result is an intense brain-drain and even more disturbing is the orientation of local research and education to encompass with what is happening in the central nations.

This scenario has reached unprecedented historical proportions in recent decades, but has also changed the vision of local priorities and solutions. Globalization together with another vision on local priorities and solutions, what some scholars name glocalization have blurred the distinction between academic and school science and mathematics and "everyday science and mathematics", the science and mathematics practiced by the common citizen. What are the science and mathematics practiced by the common citizen? The eminent mathematician Mikhail Gromov (2010) addresses the question:

Being inside our ivory tower, what can we say? We are inside this ivory tower, and we are very comfortable there. But we cannot really say much because we don't see the world well enough either. We have to go out, but that is not so easy (GROMOV in RAUSSEN \& SKAU, p. 409). 
We recognize that glocalization may lead to cases in which a global product is transformed into another form or shape in order to meet the needs of local consumers. The global product is Academic of School Science and Mathematics. It must be more adapted to the needs of those outside the Ivory Tower of academia, to the locals. This paves the way to more attention and practice of Ethnomathematics.

The obsolescence of curricula in school systems creates a disbelief in the official discourse that schooling will help to get jobs. Schools prepare for jobs that will soon be extinct and curricular innovation takes much time, energy and financial resources to be implemented. Alternative education, such as several modalities of distance education and in-job training, is increasing. Injob training is basically like artisanal apprenticeship. In prehistoric times, the transmission of technological knowledge to younger generations was essential for providing utensils, but also to integrate youth into community life, the real meaning of citizenship, as it was shown by Nuria Castañeda (2018). We may learn from the past. Ethnomathematics is practiced this way. Learning by doing. In traditional schools, this is achieved by the method of projects.

There is no way to deny that Academic or School Mathematics is essential in the modern world. Public opinion is ready to support investment in mathematical research in spite of being absolutely unable to guess what kind of research is being supported, parents invest in the mathematical education of their children, sometimes declaring that while they were in school and up to nowadays never understood mathematics, but accept that a child does an entire year again if he/she fails in the final exam - in spite of him/her.

Successful parent, even saying that they are nullities in mathematics while in school and miraculously graduated in spite of successive failures in Mathematics. But their children have to proceed — suffering and struggling — so they will not depend on miracles! Less successful parents, which did not have an opportunity of schooling and do not have a slight idea of what is Mathematics, punish their children if they don't show good marks in Mathematics. Peers and society in general regard those that get good grades in Mathematics as potential geniuses, while those that do not do well in Mathematics are regarded as stupid. Socially, this has been instrumental in the selection of elite, as it has been well studied by Pierre Samuel (1974) in his classic paper on this theme.

On the other hand, the evidence from research showing that both individual and social creativity is enhanced by self-esteem is not taken into account for those that do beautifully in the Arts or in Sports but fail in Mathematics. Let us introduce at this moment some concepts and reflections that result from what is now called Social Studies of Science or Science Policy. This is basically the study of the politics of scientific development, the backbone of funding agencies. It is 
very interesting to analyze the substitution of the colonial discourse by the discourse of aid - both multilateral, like UNESCO, and bilateral.

The nature of the deprived populations did not change in the span of fifty years. The strategies that keep them as faithful consumers have to change. These topics have in the post-war period drawn much attention and generated important studies whose results throw some lights in the production of scientific knowledge throughout history. Particularly interesting is the historiography adopted by Harold Dorn in his exciting book entitled: The Geography of Science, written in 1991. But let us not deviate from the main objective of this paper, which is the production of scientific and, in particular, mathematical knowledge.

When deciding on investments in Science and Technology, it is natural to expect social benefits. These investments have been substantial, both through funding agencies, either governmental or through aiding agencies, either bi- or multilateral. The outcomes in the so-called Third World have not been encouraging, as mentioned by the Director-General of UNESCO, Federico Mayor, in 1994: "The gap between rich and poor countries is a gap of knowledge". The gap between central nations and peripheral nations in the production of scientific knowledge is enlarging. Over $80 \%$ of the benefits of scientific and technological research benefits the First World. It is clear that scientific productivity is related to the cultural atmosphere and self-esteem. Selfesteem can hardly prevail among a population deprived of its history.

Referring to what was discussed above; the main instrument in the colonial period was to deprive the conquered peoples of their history or to produce a history "favorable" to the conqueror. There is no need to elaborate on the vision of slavery passed on by official history. We may consider, as it is frequent in discussions of policy and especially in the United Nations and other national and international agencies, measuring the production of Science and Technology, particularly Mathematics. This is the area known as Scientometrics.

It relies on several indicators and the studies of quantitative history allow us to speak of central nations, those who produce new knowledge, and peripheral nations, those who absorb new knowledge. Production and absorption of knowledge are clearly distinguishable. The sad situation is that the peripheral nations have been slow in absorbing new knowledge. The lack of infrastructure acts as a barrier for this process. This poses a basic question: what are the relations between the producers and consumers of cultural goods?

Some years ago, I introduced the Basin Metaphor as a theoretical support for this analysis (D'AMBROSIO, 2000). The main producers of knowledge (central nations) are represented by the 
main stream. The water fertilizes their margins. But the water (knowledge) does not flow up stream of the tributaries. They will produce their effect in the margins of the tributaries (peripheral nations) much later, when the waters have already flown along the stream (thus producing the gap or obsolescence of knowledge).

The water of the tributaries surely fertilizes their margins and will add and contribute, as the brain drain, to the volume of water of the main stream. This is manifest in the emigration of academics and, worst, on the subordination of laboratories and research institutions of the peripheral nations to the priorities of their major homologous in the central nations (DAMBROSIO, 1979). As an example of this, we see the efforts to entice research institutions in the peripheral nations to join major biotechnology research plans.

The co-optation of scientists in the periphery is normally done by the attractive of sending experts, in many cases scientists with a high reputation, to the periphery for short visits and conferences, by offering fellowships, by giving stipends higher than the current national salaries, by sending equipment, in many cases obsolete or already heavily used, and offering international travel to seminars and congresses. This is true in academics and, in the more developed peripheral nations, also in industry. Particularly in mathematics, we have numerous examples of such practices in the post-war period (D'AMBROSIO, 1975).

These cases have not been studied in detail as yet. Both have the common feature of producing human resources and results without any analysis of the capability of the peripheral countries to absorb and to make these resources and results useful for their priority needs. Normally this is the result of a lack of qualitative directives in Science Policy of the peripheral nations. Practically every scientific development plan in the periphery is a program entirely based in quantitative goals. Perversely financing agencies rely on, indeed stimulate, plans based on quantitative goals. Clearly, they are easier to check. But the benefits for the poor populations of the peripheral nations are practically nil.

In the basin metaphor, the sources of the rivers, the margins, both the main stream and the tributaries, correspond to ethnomathematical knowledge. Ethnomathematical knowledge, like the waters, flow fertilizing the margins of the tributary in their way and eventually mixing in a major stream, contributing to this flow. Waters of the main stream do not go up-stream through the tributaries. The notion of progress carried on by the main stream will benefit the margins of the tributary after a long way through difficult land paths - which correspond to the acquisition of knowledge from other sociocultural and environmental sources. The needs and benefits of the 
peripheral cultures - margins of the tributaries - are met only much later, and the waters of the main stream are well ahead.

\section{Final remarks}

Metaphorically, an alternative to main stream and tributaries would be a large lake, were all the sources contribute equally to the main body of water. Each source producing according to its environmental history and all the waters of the lake fertilizing all the margins. Erosion of the basin in favor of the creation of a great lake hopefully will lead to a new planetary order. This means a new world order without national boundaries. This is in the root of the growing migratory movement of refugees. Indeed this movement points to changing overcoming national boundaries. The reaction to this is the growth of Nationalism all over the world.

The new demographical scenario will inevitably produce reformulation of curricula. Syncretism in all forms of knowledge, particularly, language, religion, arts, music, and of values are impossible to avoid. Ethnomathematics will be the response for mathematical knowledge. Mathematics, as a cultural form, is not different. The emergence of new cultural behavior, particularly in observing, comparing, evaluating, organizing, inferring is a focal point of the Program Ethnomathematics.

\section{References}

AKIZUKI, YASUO. Proposal to I.C.M.I. L'Enseignement Mathématique, Genebra, v. 5, n. 4, p. 288-289, 1959.

CASTAÑEDA, Nuria. Apprenticeship in early Neolithic societies. Current Anthropology, Chicago, v. 59, n. 6, p. 716-740, dec. 2018.

D'AMBROSIO, Ubiratan. A historiographical proposal for non-western mathematics. In: SELIN, Helaine (Ed.). Mathematics across cultures: the history of non-western mathematics. Dordrecht, The Netherlands: Kluwer Academic Publisher, 2000, p. 79-92.

D'AMBROSIO, Ubiratan. Adapting the structure of education to the needs of developing countries (letter). Impact of Science on Society, v. 25, n. 1, p. 94-95, 1975.

D'AMBROSIO, Ubiratan. Knowledge transfer and the universities: a policy dilemma. Impact of Science on Society, v. 29, n. 3, p. 223-229, 1979.

DORN, Harold. The geography of science. Baltimore: The Johns Hopkins University Press, 1991.

LEPPARD, Thomas P. Social complexity and social inequality in the prehistoric Mediterranean. Current Anthropology, Chicago, v. 60, n. 3, p. 283-308, jun. 2019. 
LLOYD, Geoffrey Ernest Richard. Disciplines in the making: cross-cultural perspectives on elites, learning, and Innovation. New York: Oxford University Press, 2009.

MAYOR, Federico. Opening speech. CONFERENCE ON SCIENTIFIC AND TECHNOLOGICAL COOPERATION IN AFRICA. Nairobi, Kenya, 1994.

RAUSSEN, MARTIN; SKAU, CHRISTIAN. Interview with Mikhail Gromov. Notices of the AMS, Providence, v. 57, n. 3, p. 391-409, mar. 2010.

SAMUEL, Pierre. Mathématiques, Latin et sélection des élites. In: GROTHENDIECK, Alexandre (Ed.). Pourquoi la Mathématique? Paris: Union Générale d'Éditions, 1974, p.147-171.

WELLS, George H. The Country of the Blind. The Stand Magazine. Westminster: George Newnes, 1904. 